\title{
Next-generation panel sequencing identifies NF1 germline mutations in three patients with pheochromocytoma but no clinical diagnosis of neurofibromatosis type 1
}

\author{
Laura Gieldon 1,2,3,4, Jimmy Rusdian Masjkur5, Susan Richter', Roland Därr,8, Marcos Lahera9 , \\ Daniela Aust 2,3,4,10,11, Silke Zeugner ${ }^{10}$, Andreas Rump1, Karl Hackmann 12,3,4, Andreas Tzschach', \\ Andrzej Januszewicz ${ }^{12}$, Aleksander Prejbisz ${ }^{12}$, Graeme Eisenhofer ${ }^{5,6}$, Evelin Schrock ${ }^{1,2,3,4}$, Mercedes Robledo ${ }^{13,14}$ \\ and Barbara Klink 1,2,3,4
}

\begin{abstract}
${ }^{1}$ Institute for Clinical Genetics, Faculty of Medicine Carl Gustav Carus, TU Dresden, Dresden, Germany, ${ }^{2}$ German Cancer Consortium (DKTK), Dresden, Germany, ${ }^{3}$ German Cancer Research Center (DKFZ), Heidelberg, Germany, ${ }^{4}$ National Center for Tumor Diseases (NCT) Partner Site Dresden, Dresden, Germany, ${ }^{5}$ Department of Internal Medicine III, University Hospital Carl Gustav Carus at TU Dresden, Dresden, Germany, ${ }^{6}$ Institute of Clinical Chemistry and Laboratory Medicine, University Hospital Carl Gustav Carus at TU Dresden, Dresden, Germany, ${ }^{7}$ Department of Cardiology and Angiology I, Heart Center Freiburg University, Freiburg, Germany, ${ }^{8}$ Department of Medicine IV, Medical Center - University of Freiburg, Faculty of Medicine, University of Freiburg, Freiburg, Germany, ${ }^{9}$ Endocrinology and Nutrition Department, La Princesa University Hospital, Madrid, Spain, ${ }^{10}$ Institute for Pathology, University Hospital Carl Gustav Carus at TU Dresden, Dresden, Germany, ${ }^{11}$ Tumor- and Normal Tissuebank of the University Cancer Center/ NCT-Standort Dresden, University Hospital Carl Gustav Carus at TU Dresden, Dresden, Germany, ${ }^{12}$ Department of Hypertension, Institute of Cardiology, Warsaw, Poland, ${ }^{13}$ Hereditary Endocrine Cancer Group, Spanish National Cancer Research Centre, Madrid, Spain, and ${ }^{14}$ Centro de Investigación Biomédica en Red de Enfermedades Raras (CIBERER), Madrid, Spain
\end{abstract}

\begin{abstract}
Objective: Our objective was to improve molecular diagnostics in patients with hereditary pheochromocytoma and paraganglioma (PPGL) by using next-generation sequencing (NGS) multi-gene panel analysis. Derived from this study, we here present three cases that were diagnosed with NF1 germline mutations but did not have a prior clinical diagnosis of neurofibromatosis type 1 (NF1).

Design: We performed genetic analysis of known tumor predisposition genes, including NF1, using a multi-gene NGS enrichment-based panel applied to a total of 1029 PPGL patients. We did not exclude genes known to cause clinically defined syndromes such as NF1 based on missing phenotypic expression as is commonly practiced.

Methods: Genetic analysis was performed using NGS (TruSight Cancer Panel/customized panel by Illumina) for analyzing patients' blood and tumor samples. Validation was carried out by Sanger sequencing.

Results: Within our cohort, three patients, who were identified to carry pathogenic NF1 germline mutations, attracted attention, since none of the patients had a clinical suspicion of NF1 and one of them was initially suspected to have MEN2A syndrome due to co-occurrence of a medullary thyroid carcinoma. In these cases, one splice site, one stop and one frameshift mutation in NF1 were identified.

Conclusions: Since phenotypical presentation of NF1 is highly variable, we suggest analysis of the NF1 gene also in PPGL patients who do not meet diagnostic NF1 criteria. Co-occurrence of medullary thyroid carcinoma and PPGL was found to be a clinical decoy in NF1 diagnostics. These observations underline the value of multi-gene panel NGS for PPGL patients.

European Journal of Endocrinology

(2018) 178, K1-K9
\end{abstract}

www.eje-online.org https://doi.org/10.1530/EJE-17-0714
(C) 2018 European Society of Endocrinology Printed in Great Britain
Published by Bioscientifica Ltd. 


\section{Introduction}

Pheochromocytomas and paragangliomas (PPGL) are rare tumors derived from the adrenal medulla or extra-adrenal sympathetic and parasympathetic ganglia (1). Most of the tumors occur sporadically, but PPGLs can also be caused by genetic predisposition in association with hereditary syndromes such as multiple endocrine neoplasia type 2 (MEN2), von Hippel-Lindau disease (VHL) and neurofibromatosis type 1 (NF1) (1, 2). Furthermore, hereditary PPGLs have been identified as independent paraganglioma syndromes $1-5$ caused by germline mutations in succinate dehydrogenase $(S D H)$ genes (SDHA, SDHB, SDHC, SDHD, SDHAF2) (3, 4). Rare germline mutations of the transmembrane encoding TMEM127 gene and MYC-associated factor $\mathrm{X}(M A X)$ gene as well as the Krebs cycle-related genes MDH2, FH, IDH1 and PHD2 $(4,5,6,7,8,9)$ were also found to cause hereditary PPGL. It is now generally accepted that at least $30 \%$ of all PPGLs are caused by underlying germline mutations $(1,10)$. In children and adolescents with PPGL, germline mutations are present in up to $80 \%$ of cases $(11,12)$.

NF1 (OMIM \# 162200) (von Recklinghausen's disease) is a clinically well-characterized autosomal dominant disorder occurring in 1 per 3500 individuals (13). The condition is caused by loss-of-function mutations in NF1, a tumor suppressor gene located on chromosome $17 q 11.2(13,14,15)$. About $50 \%$ of patients have de novo spontaneous mutations that, if postzygotic, can give rise to a mosaic phenotype (16). Sequencing NF1-related tumors frequently reveals alterations of both alleles, usually one germline mutation and one acquired mutation or $\mathrm{LOH}$ of the wild-type allele $(1,13,17)$.

Although there is a high variability in phenotypic expression of NF1 even in patients with the same mutation, the clinical diagnosis is routinely based on internationally valid diagnostic criteria $(18,19)$. Pheochromocytomas occur in approximately $5-7 \%$ of NF1 patients, representing a considerably higher annual incidence than in the general population $(2-8 /$ million people) $(14,20)$. Vice versa, somatic mutations in NF1 have been reported as the most common genetic lesion in PPGLs, with NF1 mutations being identified in up to $20-25 \%$ of sporadic pheochromocytomas $(21,22,23)$. However, occurrence of PPGL is not included in the diagnostic criteria for NF1 and as a result, it is common practice to exclude NF1 as a differential diagnosis for patients with PPGL, who do not meet clinical NF1 criteria $(18,24)$.

Almost all pheochromocytomas that develop due to an underlying NF1 germline mutation produce metanephrine and normetanephrine (25). NF1 patients with pheochromocytomas are not at increased risk of malignant transformation compared to those without a known genetic cause (12\% vs $10 \%)(3,14)$, but in $14 \%$ of cases bilateral pheochromocytomas are observed. Average age of onset has been reported to be 42 years (1).

Here, we report on three cases of pathogenic germline NF1 mutations identified in patients with pheochromocytomas who did not have a prior diagnosis of NF1. In all three cases, family history was described as inconspicuous with neither pheochromocytoma nor NF1related symptoms reported in any of the family members. The patients were identified within a cohort of 1029 PPGL patients who received genetic screening by targeted NGS. In one of these patients, no signs of NF1 could be detected even by retrospective clinical examination. In the second case, retrospective examination revealed subtle signs of NF1 that initially had not been noted. Co-occurrence of a medullary thyroid carcinoma (MTC) had, however, led to the strong suspicion of an underlying MEN2A syndrome, side-tracking from the diagnosis of NF1. The third patient was unavailable for a retrospective clinical examination, but according to her physicians, no signs of NF1 were present in the patient or her family.

\section{Subjects and methods}

\section{Clinical report patient 1}

The female patient was first diagnosed with a pheochromocytoma of the right adrenal gland at 39 years of age and consequently adrenalectomy was performed in 1994. In 2008, at the age of 53 years, disease recurred on the right side and examinations additionally revealed a synchronous pheochromocytoma of the left adrenal gland, as was histologically and immunohistochemically confirmed in the course of treatment. The patient presented with episodes of palpitations, sweating and flushes and had been diagnosed with hypertension. A detailed clinical description of the patient was published in 2011 (26). Initial biochemical testing showed mildly elevated urinary outputs of metanephrine at $384 \mu \mathrm{g} /$ day (upper cutoff: $236 \mu \mathrm{g} /$ day) and normetanephrine at $904 \mu \mathrm{g} /$ day (upper cutoff: $605 \mu \mathrm{g} /$ day) as well as moderately elevated plasma concentrations of metanephrine $(170 \mathrm{pg} /$ $\mathrm{mL}$ ) (upper cutoff: $84 \mathrm{pg} / \mathrm{mL}$ ) and normetanephrine $(594 \mathrm{pg} / \mathrm{mL})$ (age-specific upper cutoff: $166 \mathrm{pg} / \mathrm{mL}$ ), but 
normal plasma catecholamines. There was no evidence of metastasis. At this point the patient was first introduced to genetic counseling.

Clinical assessment revealed multiple soft, partly pedunculated fibromas (fibroma molle) at the patients back and upper abdomen as well as few hemangiomas present mainly at the patients legs, each measuring only a few millimeters in diameter. Furthermore, the patient had macrocephaly with a head circumference of $58.5 \mathrm{~cm}$ ( $>97$ percentile, $+2.35 z$ ). Since the presence of skin lesions and macrocephaly are indicative of phacomatosis syndromes such as Cowden syndrome or NF1, dermatologic and ophthalmologic assessment regarding symptoms of the neurofibromatosis spectrum as well as biopsy and histologic evaluation of the cutaneous fibromas were initiated. However, the patient did not exhibit café-aulait spots, axillary or inguinal freckling or Lisch nodules. Neither did she show optic glioma or any neurofibromas.

Family history revealed no other relatives with PPGLs or other tumors associated with NF1 or Cowden syndrome. The only other family member with cancer was a niece, who had developed melanoma at the age of 30 years. No skin lesions similar to those of the index patient were reported in the family. The patient also stated that she had two healthy daughters and four healthy grandchildren (Fig. 1A). However, so far none of these family members was available for clinical examination regarding NF1-related features.

Importantly, besides macrocephaly and multiple pheochromocytomas, the patient did not show any other tumors or characteristics related to NF1 at the age of 53 years. The patient also did not report NF1-associated symptoms in any other of her family members. Since she did not fulfill any of the clinical diagnostic criteria for NF1, this syndrome was excluded as a differential diagnosis and therefore the NF1 gene was initially not tested in $2011(18,26)$.

\section{Clinical report: patient 2}

A second, male patient was incidentally diagnosed with biochemically positive bilateral pheochromocytomas at 56 years of age. He did not report any palpitations, flushes, episodes of sweating or headache or any other symptoms associated with catecholamine excess except for high blood pressure. Biochemical testing revealed elevated urinary outputs of metanephrine at $926 \mu \mathrm{g} /$ day (upper cutoff: $320 \mu \mathrm{g} /$ day), normetanephrine at $3188 \mu \mathrm{g} /$ day (upper cutoff: $390 \mu \mathrm{g} / \mathrm{day}$ ), epinephrine at $124 \mu \mathrm{g} / \mathrm{day}$ (upper cutoff : $27 \mu \mathrm{g} /$ day), norepinephrine at $823 \mu \mathrm{g} / \mathrm{day}$ (upper cutoff: $97 \mu \mathrm{g} / \mathrm{day}$ ) and dopamine at $653 \mu \mathrm{g} /$ day (upper cutoff: $500 \mu \mathrm{g} /$ day). The patient's past medical history included a prostatic adenocarcinoma that had been treated by radical prostatectomy two years earlier. In the course of diagnostics, a sonography revealed a thyroid nodule that was confirmed to be a MTC. Family history revealed that the patient's father had died from thyroid cancer at the age of 55 years (Fig. 1B). There was no information available, however, about the histologic type of thyroid cancer. Based on these clinical findings, MEN2A syndrome was suspected, and clinical examination was limited to the relevant aspects of this disease.

However, after the diagnosis of NF1 was made on a molecular level, a careful examination by a medical geneticist revealed 6 café-au-lait spots, mainly located on the patient's chest and in the gluteal region, with the largest one measuring $6 \times 2 \mathrm{~cm}$. He was further diagnosed with axillary and inguinal freckling and Lisch nodules. Two lesions on the patient's arm and popliteal fossa, which were primarily diagnosed as fibromata molle, were histologically re-categorized as neurofibromas. Furthermore, the patient had macrocephaly with a head circumference of $60 \mathrm{~cm}$ ( $>97$ percentile, $+1.98 \mathrm{z}$ ). An axial MRI scan showed intra-arachnoidal neurofibromas in segments T8 to L1 as well as extra-arachnoidal neurofibromas located in segments T11 to L1. A cranial MRI did not show any specific signs of NF1.

\section{Clinical report patient 3}

A third, female patient was diagnosed with hypertension up to $240 / 150 \mathrm{mmHg}$ at 22 years of age. An abdominal ultrasound was performed, showing a tumor of the left adrenal that was classified as a pheochromocytoma by CT and MIBG scans. While high plasma concentrations of normetanephrine $(4567 \mathrm{pg} / \mathrm{mL})$ (upper age-specific cutoff: $112 \mathrm{pg} / \mathrm{mL}$ ), metanephrine $(532 \mathrm{pg} / \mathrm{mL}$ ) (upper cutoff: $84 \mathrm{pg} / \mathrm{mL}$ ) and methoxytyramine $(164 \mathrm{pg} / \mathrm{mL})$ (upper cutoff: $16 \mathrm{pg} / \mathrm{mL}$ ) were detected, the patient did not show any further evidence of catecholamine excess, except for high blood pressure. Molecular diagnosis of NF1 was established by panel sequencing. Consequent re-evaluation of the patients' records, including both her past medical history and information on family history, did not reveal any NF1-related symptoms. The only notable feature was the patient's short body height of $150 \mathrm{~cm}$. The patient did not, however, consent to further medical examinations regarding subtle NF1 symptoms. 
A

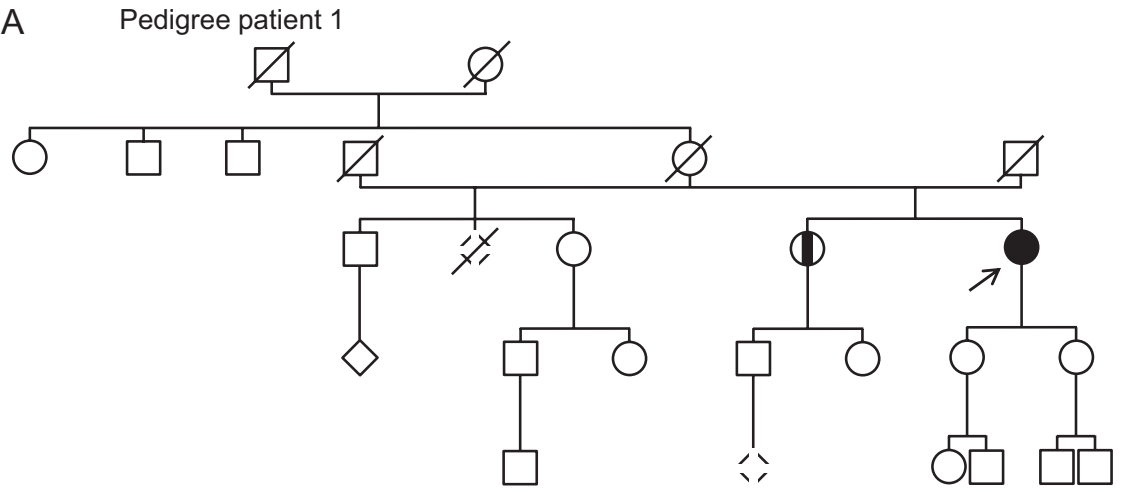

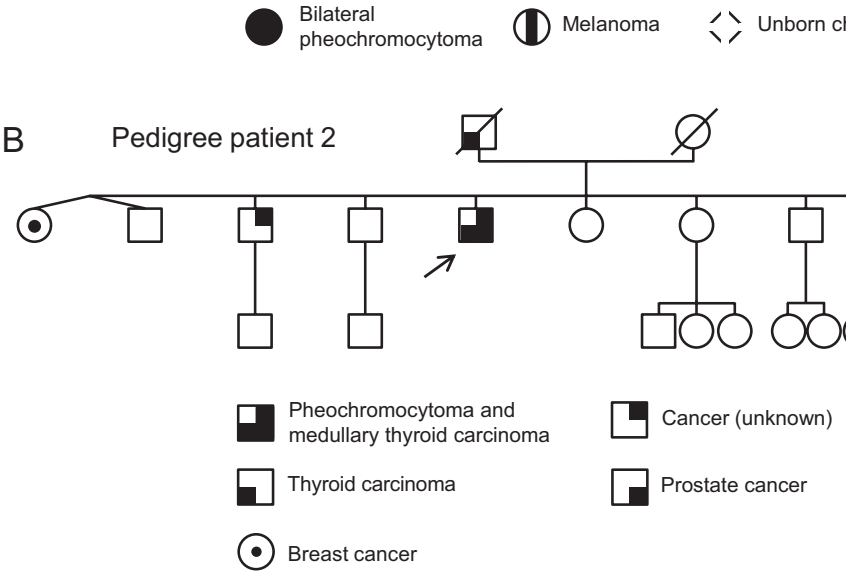

Molecular analyses

Informed consent for has been obtained from each patient prior to genetic diagnostics. Stepwise routine diagnostic Sanger sequencing of SDHA, SDHB, SDHC, SDHD, MAX, TMEM127, RET, VHL and PTEN supplemented by MLPA (multiplex-ligation assay) was performed using the first patient's blood between 2011 and 2014. When NGS technology became available for routine use, we analyzed DNA isolated from paraffin-embedded tumor tissue of the recurrent pheochromocytoma of the right adrenal gland (patient 1) using the TruSight Cancer gene panel (Illumina, San Diego, CA, USA) targeting the coding exons of 94 genes relevant in hereditary cancer syndromes, as described earlier $(27,28,29)$.

The second patient was suspected to have MEN2A syndrome, based on the rare co-occurrence of bilateral pheochromocytomas and MTC and therefore the initial molecular diagnostics was done by Sanger sequencing of the RET gene using DNA derived from the pheochromocytoma. Since no mutation could be detected, DNA derived from the thyroid carcinoma was analyzed with regards to somatic mutations in RET, NRAS, KRAS and MERTK. When again the analysis did not confirm a mutation, a panel-based NGS approach, using

\section{Figure 1}

Pedigrees of the families of patient 1 (A) and patient 2 (B). (A) According to patient 1 , none of her family members suffered from any symptoms related to NF1. There was no further information available on the father's family side. (B) Note the patient's father who also suffered from medullary thyroid carcinoma. a customized panel including all PPGL-associated genes, was applied to the pheochromocytoma-derived DNA (30).

With no clinical suspicion of NF1, the third patient was initially tested for mutations by Sanger sequencing as well and in this case only the SDH, RET and VHL genes were targeted. When no mutation could be detected, panel sequencing was initiated due to the early age of PPGL onset and large tumor size $(6 \times 5 \times 6 \mathrm{~cm})$ in this patient. Validation of the identified NF1 mutations was performed by Sanger sequencing. DNA from all three patients' blood samples.

\section{Results}

\section{Patient 1}

Using NGS a pathogenic splice-site mutation in NF1: NM_000267.3:c.6084+1G>A was revealed in a homozygous state in pheochromocytoma tumor tissue (Fig. 2A). The same mutation had already been described as being pathogenic by De Luca and coworkers (31). The variant was proven to be present in the patient's blood in heterozygous state and validated in homozygous state in tumor tissue by Sanger sequencing (Fig. 2B and C). Other 


\section{Figure 2}
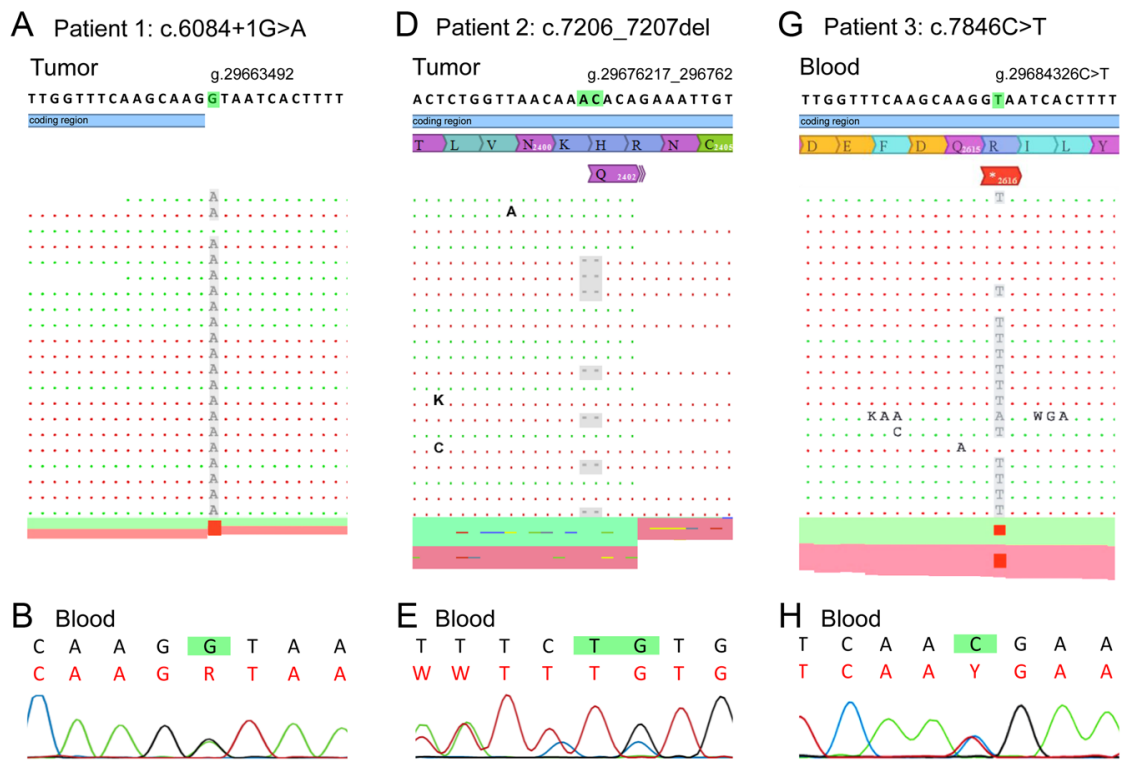
$\begin{array}{llllllll}W & W & T & T & T & G & T & G\end{array}$

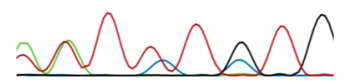

H Blood

$\begin{array}{llllll}C & A & A & A & A\end{array}$

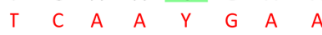

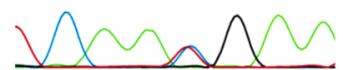

C Tumor

C A $A$ A $\quad G \quad T \quad A \quad A$

C A $A \quad G \quad A \quad T \quad A \quad A$

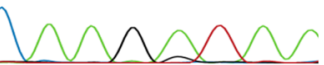

F Tumor

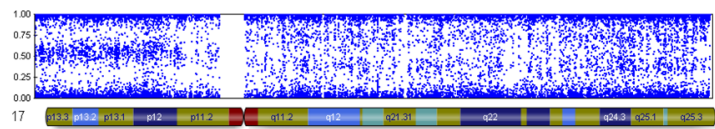

Patient 1: (A) NGS data generated by sequencing tumor-derived DNA. The homozygous splice-site mutation c. $6084+1 \mathrm{G}>\mathrm{A}$ is marked in gray. Forward reads are displayed in green, backward reads are displayed in red. (B) Sanger sequencing confirmed the mutation to be present in heterozygous state in blood and $(C)$ in a homozygous state in the tumor. Patient 2: (D) NGS data generated by sequencing tumor-derived DNA. The heterozygous deletion c.7207_7207del is marked in gray. (E) Sanger sequencing confirmed the mutation to be present in heterozygous state in blood. (F) While sequencing data did not indicate $\mathrm{LOH}$ in tumor tissue, a SNP array performed from tumor-derived DNA indicated loss of the long arm of chromosome 17 (17q-), including the NF1 gene located on 17q11.2. Patient 3: (G) Sequencing data generated from blood-derived DNA from patient 3. The heterozygous nonsense mutation c. $7846 \mathrm{C}>\mathrm{T}$ is marked in green. (H) The sequencing results were validated by Sanger sequencing. variants identified on chromosome 17 were also found in a homozygous state in tumor tissue. Therefore, loss of heterozygosity in NF1 was ascertained to be the underlying mechanism of pathogenesis in this patient's tumor. In line with the framework for variant interpretation in PPGL outlined in the Consensus Statement on NGS-based diagnostic testing of PPGL, the variant was classified as a class 5 pathogenic mutation (10).

\section{Patient 2}

Since Sanger sequencing of RET, HRAS, KRAS and MERTK using MTC-derived DNA did not identify any pathogenic mutations, a panel-based NGS approach was used for analyzing DNA derived from the pheochromocytoma. By this, a heterozygous pathogenic germline mutation was revealed in NF1: NM_000267.3: c.7206_7207del (p.His2402Gln $f s^{*} 4$ ) (Fig. 2D). In this mutation, a deletion of two bases leads to a frameshift and a subsequent truncation of the protein, thereby impeding protein function. While the variant has never been reported in literature, it is not listed in the ExAc database (http:// exac.broadinstitute.org/), which comprises over 66000 healthy individuals. In the ClinVar database (https://www.ncbi.nlm.nih.gov/clinvar/), the variant is listed as a pathogenic mutation. With regards to the truncating mutation mechanism in the middle of the protein (exon 29 of 58) the variant was therefore also regarded as a class 5 pathogenic mutation. The mutation could also be verified to be present in the germline by Sanger sequencing (Fig. 2E) and was further validated in heterozygous state in the MTC as well. While sequencing data did not show any evidence of a loss of heterozygosity or a somatic, compound heterozygous variant in NF1 in both tumors, a SNP-array performed from pheochromocytoma-derived DNA indicated possible monoallelic loss of the q-arm of chromosome 17, where NF1 is located (Fig. 2F). This discrepancy might be explained by contamination of tumor tissue with normal cells. 


\section{Patient 3}

Analyzing DNA extracted from the patient's blood and applying the NGS approach revealed a heterozygous nonsense mutation in NF1: NM_000267.3:c.7846C $>$ T, p.Arg2616* (Fig. 2G). In this case, transition from $C$ to $\mathrm{T}$ at position 7846 leads to preliminary chain termination at codon 2612 within exon 45 . The variant has been described before in a patient with typical symptoms of NF1 including cutaneous involvement and plexiform neurofibromas (32) and was therefore also classified as class 5 pathogenic variant. The variant was validated by Sanger sequencing using blood-derived DNA (Fig. 2H). In this case, no tumor tissue was available for genetic testing.

\section{Discussion}

NF1 is one of the largest genes, comprising $360 \mathrm{~kb}$ and 63 exons. Consequently, sequencing NF1 has long been a laborious and expensive task (13). For this reason, diagnosis of NF1 is commonly based on clinical criteria only and does not routinely include validation on a molecular basis. To date, healthy individuals from families with known NF1 have not routinely been sequenced for NF1 mutations. The same is true for individuals with PPGL, as they typically do not get tested for NF1 mutations if clinical criteria for NF1 are not met (24, 33). Today, however, with cost-effective NGS-sequencing methods at our hands, NF1 can easily be included in routine molecular diagnostics for patients with PPGL. We thereby identified pathogenic NF1 mutations in three PPGL patients who would otherwise not have caught our attention as being suspicious for NF1.

We therefore propose to include the NF1 gene into routine diagnostics for PPGL patients even if there are no clinical symptoms suggestive of NF1. Analyzing tumorderived DNA further broadens the spectrum of diagnostic possibilities providing the opportunity to also diagnose mutations in a mosaic state, which could ultimately lead to a milder phenotype. These propositions are in line with the recommendations summarized in the Consensus Statement on NGS-based diagnostic testing of PPGLs, where targeted gene panels are characterized as the gold standard in the diagnostics of this highly heterogeneous disease (10).

Our second patient showed typical but subtle clinical signs of NF1 in retrospective clinical examination. A similar case was reported in 2006, where the patient also had Lisch nodules, café-au-lait spots and axillary freckling, which were not recognized by several physicians. Comparable to our case the clinical diagnosis of NF1 was not made until genetic testing revealed a pathogenic NF1 mutation (34). It seems, therefore, that routine clinical examination performed in the context of PPGL diagnostics does not suffice NF1 detection and occurrence of PPGL should prompt a specific and detailed clinical examination for subtle signs of this syndrome.

In our patient, the co-occurrence of a MTC additionally constituted a clinical decoy for MEN2A syndrome. This is of special interest since, to the best of our knowledge, the co-occurrence of pheochromocytoma, MTC and hyperparathyroidism in NF1 patients has been reported only three times in the literature $(35,36,37)$. To exclude a somatic mutation in RET as an independent cause for MTC development in this patient, analysis of tumorderived DNA for RET mutations was performed. Since no somatic RET mutation was detected and with this being the fourth patient described with a mutation in NF1 and occurrence of pheochromocytomas as well as MTC, we propose NF1 should be considered in pheochromocytoma patients showing the full spectrum of MEN2A syndrome if no mutation can be identified in the RET gene. However, it cannot be excluded that the occurrence of an MTC in patient 2 was a sporadic event independent of the NF1 germline mutation.

Although we could identify the underlying NF1 germline mutations in the PPGL patients described here using NGS, it is nevertheless important to consider the limitations of the technique (38). Current panel sequencing is limited to the coding exons and adjacent intronic regions of target regions. Therefore splice-site mutations can be detected while deep intronic variants may be missed. Additionally, larger genomic rearrangements (translocations, deletions and inversions) cannot robustly be detected by NGS. Also, while the approach in general is better at detecting mosaicism than Sanger sequencing, low-grade mosaicism may still be missed.

NF1 is known to be phenotypically heterogeneous even in patients carrying the very same mutation. Considering that we identified an NF1 germline mutation in a patient who did not fulfill the diagnostic NF1 criteria, as well as in a patient in whom the NF1 symptoms where overlooked during initial clinical examination, it seems possible that the condition has long been underdiagnosed. Using NGS panel diagnostics for PPGL patients might reveal that a higher percentage of these tumors than originally presumed in the literature are due to NF1 germline mutations. This assumption is supported by the fact that somatic NF1 mutations have frequently been identified in PPGL (39). Vice versa, it has lately 
been proposed that occurrence of PPGLs in NF1 patients might also have been underestimated, since in the past, biochemical testing was only recommended if patients developed hypertension. With increasing recognition of normotensive cases of the tumor in NF1 $(40,41)$ and findings of pheochromocytomas in 13\% of patients with NF1 at autopsy $(14,35)$, it is now being advocated that patients with NF1 mutations should be screened for PPGLs at least once every three years $(35,40,41)$. In line with these findings of asymptomatic or inconspicuous PPGL in NF1 patients, both our second and third patient did not report any symptoms of catecholamine excess except for hypertension (40). The genotypephenotype correlation in our patients is consistent with earlier reports of PPGL in NF1 mutation carriers where pheochromocytomas producing metanephrine and normetanephrine were predominantly observed (25). Therefore, surveillance measurements for PPGL in NF1 patients could be planned in accordance with these findings, specifically targeting catecholamine producing PPGL. It is noteworthy that, while it has been reported that the majority of NF1-related pheochromocytomas occur unilaterally, two of our patients had bilateral, and in the case of patient 1 , even recurrent pheochromocytomas $(35,40)$. This, again, emphasizes the broad phenotypic spectrum of NF1 underlining the need to consider NF1 as a differential diagnosis both in unilateral and bilateral pheochromocytomas. We recommended close follow-up examinations for our patients with regard to PPGL as well as surveillance for other NF1-related symptoms. Additionally, we offered predictive NF1 mutation testing to healthy relatives. So far, however, none of the relatives consented to genetic testing.

In summary, identifying pathogenic NF1 mutations in three PPGL patients unsuspicious for NF1 led us to conclude that ideally sequencing of NF1 should be included in routine PPGL diagnostics. With NGS currently advancing to be the predominant diagnostic approach for PPGL (42), inclusion of the NF1 gene in targeted sequencing and analytic algorithms seems to be a reasonable approach. We additionally suggest sequencing of tumor tissue since mosaicism might not be detected in blood samples. Additionally, we recommend thorough examination specifically for NF1 symptoms in all patients with pheochromocytomas by an experienced geneticist. The three cases presented here show the importance of keeping an open mind even if clinical stigmata do not provide the full clinical evidence of NF1 and, in addition, the importance of being wary of clinical decoys (e.g. MTC). Knowledge of the underlying NF1 mutations prompted us to adjust preventive measures for our patients and their family members and to offer predictive testing to healthy relatives.

\section{Declaration of interests}

The authors declare that there is no conflict of interest that could be perceived as prejudicing the impartiality of this case report.

\section{Funding}

This work was supported by the Deutsche Forschungsgemeinschaft (grant numbers RI 2684/1-1; KL 2541/2-1) and the Fondo de Investigaciones Sanitarias (project PI14/00240), co-financed by FEDER.

\section{Acknowledgements}

The authors would like to thank the patients and their families for participating in this work. They further thank Alexander Krüger and Eva Gerlach for excellent technical support.

\section{References}

1 Welander J, Soderkvist P \& Gimm O. Genetics and clinical characteristics of hereditary pheochromocytomas and paragangliomas. Endocrine-Related Cancer 201118 R253-R276. (https://doi.org/10.1530/ERC-11-0170)

2 Maher ER \& Eng C. The pressure rises: update on the genetics of phaeochromocytoma. Human Molecular Genetics 200211 2347-2354. (https://doi.org/10.1093/hmg/11.20.2347)

3 Favier J, Briere JJ, Strompf L, Amar L, Filali M, Jeunemaitre X, Rustin P \& Gimenez-Roqueplo AP. Hereditary paraganglioma/ pheochromocytoma and inherited succinate dehydrogenase deficiency. Hormone Research 200563 171-179. (https://doi. org/10.1159/000084685)

4 Comino-Mendez I, Gracia-Aznarez FJ, Schiavi F, Landa I, LeandroGarcia LJ, Leton R, Honrado E, Ramos-Medina R, Caronia D, Pita G et al. Exome sequencing identifies MAX mutations as a cause of hereditary pheochromocytoma. Nature Genetics 201143 663-667. (https://doi.org/10.1038/ng.861)

5 Qin Y, Yao L, King EE, Buddavarapu K, Lenci RE, Chocron ES, Lechleiter JD, Sass M, Aronin N, Schiavi F et al. Germline mutations in TMEM127 confer susceptibility to pheochromocytoma. Nature Genetics 201042 229-233. (https://doi.org/10.1038/ng.533)

6 Cascon A, Comino-Mendez I, Curras-Freixes M, de Cubas AA, Contreras L, Richter S, Peitzsch M, Mancikova V, Inglada-Perez L, Perez-Barrios A et al. Whole-exome sequencing identifies MDH2 as a new familial paraganglioma gene. Journal of the National Cancer Institute 2015 107. (https://doi.org/10.1093/jnci/djv053)

7 Ladroue C, Carcenac R, Leporrier M, Gad S, Le Hello C, GalateauSalle F, Feunteun J, Pouyssegur J, Richard S \& Gardie B. PHD2 mutation and congenital erythrocytosis with paraganglioma. New England Journal of Medicine 2008359 2685-2692. (https://doi. org/10.1056/NEJMoa0806277)

8 Castro-Vega LJ, Buffet A, De Cubas AA, Cascon A, Menara M, Khalifa E, Amar L, Azriel S, Bourdeau I, Chabre O et al. Germline mutations in FH confer predisposition to malignant pheochromocytomas and paragangliomas. Human Molecular Genetics 201423 2440-2446. (https://doi.org/10.1093/hmg/ddt639)

9 Kirmani S \& Young WF. Hereditary paragangliomapheochromocytoma syndromes. In Gene Reviews(R). Eds RA Pagon, MP Adam, HH Ardinger, SE Wallace, A Amemiya, LJH Bean, TD Bird, N Ledbetter, HC Mefford, RJH Smith et al. Seattle, WA: University of 
Washington, Seattle University of Washington, Seattle. GeneReviews is a registered trademark of the University of Washington, Seattle. All rights reserved, 1993

10 Toledo RA, Burnichon N, Cascon A, Benn DE, Bayley JP, Welander J, Tops CM, Firth H, Dwight T, Ercolino T et al. Consensus statement on next-generation-sequencing-based diagnostic testing of hereditary phaeochromocytomas and paragangliomas. Nature Reviews Endocrinology 201713 233-247. (https://doi.org/10.1038/ nrendo.2016.185)

11 Bausch B, Wellner U, Bausch D, Schiavi F, Barontini M, Sanso G, Walz MK, Peczkowska M, Weryha G, Dall'igna P et al. Long-term prognosis of patients with pediatric pheochromocytoma. EndocrineRelated Cancer 201421 17-25. (https://doi.org/10.1530/ERC-13-0415)

12 Pamporaki C, Hamplova B, Peitzsch M, Prejbisz A, Beuschlein F, Timmers HJ, Fassnacht M, Klink B, Lodish M, Stratakis CA et al. Characteristics of pediatric vs adult pheochromocytomas and paragangliomas. Journal of Clinical Endocrinology and Metabolism 2017 102 1122-1132. (https;//doi.org/10.1210/jc.2016-3829)

13 Boyd KP, Korf BR \& Theos A. Neurofibromatosis type 1. Journal of the American Academy of Dermatology 200961 1-14. (https://doi. org/10.1016/j.jaad.2009.04.001)

14 Fishbein L \& Nathanson KL. Pheochromocytoma and paraganglioma: understanding the complexities of the genetic background. Cancer Genetics 2012205 1-11. (https://doi. org/10.1016/j.cancergen.2012.01.009)

15 Pasmant E, Parfait B, Luscan A, Goussard P, Briand-Suleau A, Laurendeau I, Fouveaut C, Leroy C, Montadert A, Wolkenstein P et al. Neurofibromatosis type 1 molecular diagnosis: what can NGS do for you when you have a large gene with loss of function mutations? European Journal of Human Genetics 201523 596-601. (https://doi. org/10.1038/ejhg.2014.145)

16 Kehrer-Sawatzki H \& Cooper DN. Mosaicism in sporadic neurofibromatosis type 1: variations on a theme common to other hereditary cancer syndromes? Journal of Medical Genetics $2008 \mathbf{4 5}$ 622-631. (https://doi.org/10.1136/jmg.2008.059329)

17 Bausch B, Borozdin W, Mautner VF, Hoffmann MM, Boehm D, Robledo M, Cascon A, Harenberg T, Schiavi F, Pawlu C et al. Germline NF1 mutational spectra and loss-of-heterozygosity analyses in patients with pheochromocytoma and neurofibromatosis type 1 . Journal of Clinical Endocrinology and Metabolism 200792 2784-2792. (https://doi.org/10.1210/jc.2006-2833)

18 Neurofibromatosis. Conference statement. National Institutes of Health Consensus Development Conference. Archives of Neurology 198845 575-578.

19 Ferner RE, Huson SM, Thomas N, Moss C, Willshaw H, Evans DG, Upadhyaya M, Towers R, Gleeson M, Steiger C et al. Guidelines for the diagnosis and management of individuals with neurofibromatosis 1. Journal of Medical Genetics 200744 81-88. (https://doi.org/10.1136/jmg.2006.045906)

20 Walther MM, Reiter R, Keiser HR, Choyke PL, Venzon D, Hurley K, Gnarra JR, Reynolds JC, Glenn GM, Zbar B et al. Clinical and genetic characterization of pheochromocytoma in von HippelLindau families: comparison with sporadic pheochromocytoma gives insight into natural history of pheochromocytoma. Journal of Urology 1999162 659-664. (https://doi.org/10.1097/00005392199909010-00004)

21 Dahia PL. Pheochromocytoma and paraganglioma pathogenesis: learning from genetic heterogeneity. Nature Reviews Cancer 201414 108-119. (https://doi.org/10.1038/nrc3648)

22 Burnichon N, Buffet A, Parfait B, Letouze E, Laurendeau I, Loriot C, Pasmant E, Abermil N, Valeyrie-Allanore L, Bertherat J et al. Somatic NF1 inactivation is a frequent event in sporadic pheochromocytoma. Human Molecular Genetics 201221 5397-5405. (https://doi. org/10.1093/hmg/dds374)

23 Welander J, Soderkvist P \& Gimm O. The NF1 gene: a frequent mutational target in sporadic pheochromocytomas and beyond.
Endocrine-Related Cancer 201320 C13-C17. (https://doi.org/10.1530/ ERC-13-0046)

24 Pandit R, Khadilkar K, Sarathi V, Kasaliwal R, Goroshi M, Khare S, Nair S, Raghavan V, Dalvi A, Hira P et al. Germline mutations and genotype-phenotype correlation in Asian Indian patients with pheochromocytoma and paraganglioma. European Journal of Endocrinology 2016175 311-323. (https://doi.org/10.1530/EJE-160126)

25 Eisenhofer G, Lenders JW, Timmers H, Mannelli M, Grebe SK, Hofbauer LC, Bornstein SR, Tiebel O, Adams K, Bratslavsky G et al. Measurements of plasma methoxytyramine, normetanephrine, and metanephrine as discriminators of different hereditary forms of pheochromocytoma. Clinical Chemistry 201157 411-420. (https:// doi.org/10.1373/clinchem.2010.153320)

26 Darr R, Eisenhofer G, Kotzerke J, Zophel K, Stroszczynski C, Deinum J, Schultze Kool LJ, Pistorius S, Neumann H, Bornstein SR et al. Is there still a place for adrenal venous sampling in the diagnostic localization of pheochromocytoma? Endocrine 201140 75-79. (https://doi.org/10.1007/s12020-011-9471-4)

27 Schroeder C, Faust U, Sturm M, Hackmann K, Grundmann K, Harmuth F, Bosse K, Kehrer M, Benkert T, Klink B et al. HBOC multi-gene panel testing: comparison of two sequencing centers. Breast Cancer Research and Treatment 2015152 129-136. (https://doi. org/10.1007/s10549-015-3429-9)

28 Rump A, Benet-Pages A, Schubert S, Kuhlmann JD, Janavicius R, Machackova E, Foretova L, Kleibl Z, Lhota F, Zemankova P et al. Identification and functional testing of ERCC2 mutations in a multinational cohort of patients with familial breast- and ovarian cancer. PLOS Genetics 201612 e1006248. (https://doi.org/10.1371/journal. pgen.1006248)

29 Pistorius S, Klink B, Pablik J, Rump A, Aust D, Garzarolli M, Schrock E $\&$ Schackert HK. An unusual case of Cowden syndrome associated with ganglioneuromatous polyposis. Hereditary Cancer in Clinical Practice 201614 11. (https://doi.org/10.1186/s13053-016-0051-8)

30 Curras-Freixes M, Pineiro-Yanez E, Montero-Conde C, ApellanizRuiz M, Calsina B, Mancikova V, Remacha L, Richter S, Ercolino T, Rogowski-Lehmann $\mathrm{N}$ et al. PheoSeq: a targeted next-generation sequencing assay for pheochromocytoma and paraganglioma diagnostics. Journal of Molecular Diagnostics 201719 575-588. (https://doi.org/10.1016/j.jmoldx.2017.04.009)

31 De Luca A, Schirinzi A, Buccino A, Bottillo I, Sinibaldi L, Torrente I, Ciavarella A, Dottorini T, Porciello R, Giustini S et al. Novel and recurrent mutations in the NF1 gene in Italian patients with neurofibromatosis type 1. Human Mutation 200423 629. (https;//doi. org/10.1002/humu.9245)

32 Upadhyaya M, Maynard J, Osborn M, Huson SM, Ponder M, Ponder BA \& Harper PS. Characterisation of germline mutations in the neurofibromatosis type 1 (NF1) gene. Journal of Medical Genetics 199532 706-710. (https://doi.org/10.1136/jmg.32.9.706)

33 Jafri M \& Maher ER. The genetics of phaeochromocytoma: using clinical features to guide genetic testing. European Journal of Endocrinology 2012166 151-158. (https://doi.org/10.1530/EJE-110497)

34 Bausch B, Koschker AC, Fassnacht M, Stoevesandt J, Hoffmann MM, Eng C, Allolio B \& Neumann HP. Comprehensive mutation scanning of NF1 in apparently sporadic cases of pheochromocytoma. Journal of Clinical Endocrinology and Metabolism 200691 3478-3481. (https:// doi.org/10.1210/jc.2006-0780)

35 Moramarco J, El Ghorayeb N, Dumas N, Nolet S, Boulanger L, Burnichon N, Lacroix A, Elhaffaf Z, Gimenez Roqueplo AP, Hamet P et al. Pheochromocytomas are diagnosed incidentally and at older age in neurofibromatosis type 1. Clinical Endocrinology 201786 332-339. (https://doi.org/10.1111/cen.13265)

36 Gkaliagkousi E, Erlic Z, Petidis K, Semertzidis P, Doumas M, Zamboulis C, Neumann HP \& Douma S. Neurofibromatosis type 1: should we screen for other genetic syndromes? A case report of 
co-existence with multiple endocrine neoplasia 2A. European Journal of Clinical Investigation 200939 828-832. (https://doi.org/10.1111/ j.1365-2362.2009.02174.x)

37 Cotesta D, Erlic Z, Petramala L, Verrienti A, Cavallaro G, Giustini S, Divona L, Polistena A, Ciardi A, D'Erasmo E et al. Coincidence of neurofibromatosis type 1 and multiple endocrine neoplasia type 2. Endocrinologist 200818 277-281. (https://doi.org/10.1097/ TEN.0b013e3181913188)

38 Richter S, Klink B, Nacke B, de Cubas AA, Mangelis A, Rapizzi E, Meinhardt M, Skondra C, Mannelli M, Robledo M et al. Epigenetic mutation of the succinate dehydrogenase $\mathrm{C}$ promoter in a patient with two paragangliomas. Journal of Clinical Endocrinology and Metabolism 2016101 359-363. (https://doi.org/10.1210/jc.20153856)

39 Luchetti A, Walsh D, Rodger F, Clark G, Martin T, Irving R, Sanna M, Yao M, Robledo M, Neumann HP et al. Profiling of somatic mutations in phaeochromocytoma and paraganglioma by targeted next generation sequencing analysis. International Journal of Endocrinology 20152015138573.

40 Kepenekian L, Mognetti T, Lifante JC, Giraudet AL, Houzard C, Pinson S, Borson-Chazot F \& Combemale P. Interest of systematic screening of pheochromocytoma in patients with neurofibromatosis type 1. European Journal of Endocrinology 2016175 335-344. (https:// doi.org/10.1530/EJE-16-0233)

41 Gruber LM, Erickson D, Babovic-Vuksanovic D, Thompson GB, Young WF Jr \& Bancos I. Pheochromocytoma and paraganglioma in patients with neurofibromatosis type 1. Clinical Endocrinology 2016 86 141-149 (https://doi.org/10.1111/cen.13163)

42 Pillai S, Gopalan V \& Lam AK. Review of sequencing platforms and their applications in phaeochromocytoma and paragangliomas. Critical Reviews in Oncology/Hematology 2017116 58-67. (https://doi. org/10.1016/j.critrevonc.2017.05.005)

Received 28 August 2017

Revised version received 13 November 2017

Accepted 20 November 2017 